Effect of fox, pig, sheep, and poultry bile on the establishment of domestic and sylvatic species of Trichinella in rats

Theodoropoulos, G.; Styliara, M.; Petrakos, M.; Kapel, C.M.O.

Published in:

Parazitologiya

DOI:

$10.1017 / \mathrm{S} 003118200300307 \mathrm{X}$

Publication date:

2003

Document version

Publisher's PDF, also known as Version of record

Citation for published version (APA):

Theodoropoulos, G., Styliara, M., Petrakos, M., \& Kapel, C. M. O. (2003). Effect of fox, pig, sheep, and poultry bile on the establishment of domestic and sylvatic species of Trichinella in rats. Parazitologiya, 126, 461-464. https://doi.org/10.1017/S003118200300307X 


\title{
Effect of fox, pig, sheep, and poultry bile on the establishment of domestic and sylvatic species of Trichinella in rats
}

\author{
G. THEODOROPOULOS ${ }^{1 *}$, M. STYLIARA ${ }^{1}$, M. PETRAKOS ${ }^{1}$ \\ and C. M. O. KAPEL ${ }^{2}$ \\ ${ }^{1}$ Department of Anatomy and Physiology of Farm Animals, Faculty of Animal Science, Agricultural University of Athens, \\ 75 Iera Odos, Votanikos, Athens 11855 , Greece \\ ${ }^{2}$ Danish Centre for Experimental Parasitology, The Royal Veterinary and Agricultural University, Dyrlaegevej 100, \\ DK-1870 Frederiksberg C, Denmark
}

(Received 14 September 2002; revised 13 December 2002; accepted 16 December 2002)

\section{SUMMARY}

\begin{abstract}
Most sylvatic species of Trichinella are known to have poor infectivity to rats, but in the present study oral administration of bile from other hosts appeared to modify this infectivity. A total of 75 rats were inoculated in groups of 25 with 3 species of Trichinella (T. spiralis, T. nativa, and T. nelsoni) and each group of rats was given per os daily doses of bile from pig, sheep, chicken and fox respectively $(4 \times 5$ rats). As a control 1 group of 5 rats was given daily doses of water. Whereas, the addition of bile did not increase the establishment of T. spiralis, fox bile had a significant positive effect on the establishment of muscle larvae of T. nativa and T. nelsoni. Addition of bile to cultures of the same Trichinella species had an overall negative effect on the in vitro survival of larvae. The present observation that carnivore bile favours the establishment of sylvatic Trichinella may explain why carnivores are equally receptive to all Trichinella species.
\end{abstract}

Key words: Trichinella spiralis, Trichinella nativa, Trichinella nelsoni, bile, rats.

\section{INTRODUCTION}

Foxes have a high susceptibility to all species of Trichinella spp. (Kapel, 2000) and as a main reservoir in Europe (Pozio, 1998) they are often used in the role of indicator population for monitoring wildlife trichinellosis. This uniform high infectivity of the Trichinella species is markedly different from what is found in rodents and herbivorous animals where domestic Trichinella spiralis has a significantly higher infectivity than sylvatic species (Kapel, 2000). The mechanisms underlying these differences have not been investigated in detail up to now. It is known that chickens are resistant to infective $T$. spiralis larvae and this resistance has been linked to the deleterious effects that extracts from the small intestine, pancreas, and bile of chickens have on the larvae (Barriga, 1981). Other authors (Smyth, Gemmell \& Smyth, 1969) have found that differences in the composition of bile between definitive host species may influence host specificity in Echinococcus granulosus. The objective of the present study was to evaluate the effect of bile from fox, pig, sheep, and poultry on the infectivity to rats of domestic and sylvatic Trichinella species. In addition, the in vitro survival

* Corresponding author: Department of Anatomy and Physiology of Farm Animals, Faculty of Animal Science, Agricultural University of Athens, 75 Iera Odos, Votanikos, Athens 11855, Greece. Tel: + 30210 5294387. Fax: +30210 5294388. E-mail:gtheo@aua.gr of muscle larvae was monitored in cultures where bile from the same animals was added.

MATERIALS AND METHODS

Species and source of muscle larvae and bile

The Trichinella species used were $T$. spiralis (ISS004), T. nativa (ISS042), and T. nelsoni (ISS037), which have been maintained by serial passages in mice. Larvae were released from thoroughly minced mouse muscle tissue by digestion $\left(1 \mathrm{~L} \mathrm{H}_{2} \mathrm{O}\right.$, $10 \mathrm{~g} 1: 10000 \mathrm{IU}$ Pepsin, $10 \mathrm{ml}$ of $37 \% \mathrm{HCl}$ ) for $1 \mathrm{~h}$ at $37^{\circ} \mathrm{C}$.

Bile was collected from foxes, pigs, sheep, and chicken and stored at $-80{ }^{\circ} \mathrm{C}$ prior to experimentation.

In vivo study

A total of 75 female inbred 10 -week-old Wistar rats were inoculated per os through a feeding needle with 1000 larvae in 3 groups of 25 rats with respectively T. spiralis, T. nativa and T. nelsoni and divided further in 5 groups of 5 rats. Four groups received diluted bile from fox, pig, sheep or chicken respectively and 1 control group received water. For 21 days, rats were administered daily portions $(0.5 \mathrm{ml})$ of bile (diluted $1: 2 \cdot 6$ in tap water) or water respectively. All inoculations during the experiments were done after anaesthesia with $\mathrm{CO}_{2}$. The rats were sacrificed 
Table 1. Reproductive capacity index (RCI : larvae recovered/larvae inoculated) in rats

\begin{tabular}{|c|c|c|c|c|c|c|}
\hline \multirow[b]{2}{*}{ Inoculum } & \multicolumn{2}{|c|}{ T. spiralis } & \multicolumn{2}{|c|}{ T. nativa } & \multicolumn{2}{|c|}{ T. nelsoni } \\
\hline & $\mathrm{RCI}$ & Mean \pm s.D. & $\mathrm{RCI}$ & Mean \pm s.D. & $\mathrm{RCI}$ & Mean \pm s.D. \\
\hline \multirow[t]{5}{*}{ Fox bile } & $13 \cdot 770$ & \multirow[t]{5}{*}{$66 \cdot 963 \pm 93 \cdot 84$} & $0 \cdot 027$ & \multirow{5}{*}{$0 \cdot 045 \pm 0 \cdot 03$} & $0 \cdot 014$ & \multirow{5}{*}{$0 \cdot 0186 \pm 0 \cdot 0097$ * } \\
\hline & $15 \cdot 300$ & & $0 \cdot 016$ & & $0 \cdot 013$ & \\
\hline & $33 \cdot 525$ & & 0.093 & & $0 \cdot 010$ & \\
\hline & $38 \cdot 520$ & & $0 \cdot 065$ & & $0 \cdot 034$ & \\
\hline & $233 \cdot 700$ & & $0 \cdot 024$ & & $0 \cdot 022$ & \\
\hline \multirow{5}{*}{ Pig bile } & $18 \cdot 150$ & \multirow{5}{*}{$9 \cdot 950 \pm 8 \cdot 41$} & $0 \cdot 000$ & \multirow{5}{*}{$0 \cdot 000 \pm 0 \cdot 00$} & $0 \cdot 004$ & \multirow[t]{5}{*}{$0 \cdot 0038 \pm 0 \cdot 0013$} \\
\hline & $10 \cdot 350$ & & $0 \cdot 000$ & & $0 \cdot 005$ & \\
\hline & $1 \cdot 350$ & & & & $0 \cdot 003$ & \\
\hline & & & & & $0 \cdot 002$ & \\
\hline & & & & & $0 \cdot 005$ & \\
\hline \multirow[t]{5}{*}{ Sheep bile } & $5 \cdot 400$ & \multirow[t]{5}{*}{$15 \cdot 510 \pm 8 \cdot 35$} & $0 \cdot 000$ & \multirow{5}{*}{$0 \cdot 000 \pm 0 \cdot 00$} & $0 \cdot 005$ & \multirow{5}{*}{$0 \cdot 0024 \pm 0 \cdot 0018$} \\
\hline & $17 \cdot 400$ & & $0 \cdot 000$ & & $0 \cdot 003$ & \\
\hline & $8 \cdot 250$ & & $0 \cdot 000$ & & $0 \cdot 002$ & \\
\hline & $22 \cdot 650$ & & $0 \cdot 000$ & & $0 \cdot 000$ & \\
\hline & $23 \cdot 850$ & & $0 \cdot 000$ & & $0 \cdot 002$ & \\
\hline \multirow[t]{4}{*}{ Chicken bile } & $12 \cdot 825$ & \multirow[t]{4}{*}{$13 \cdot 894 \pm 4 \cdot 24$} & $0 \cdot 000$ & \multirow[t]{4}{*}{$0 \cdot 000 \pm 0 \cdot 00$} & $0 \cdot 000$ & \multirow[t]{4}{*}{$0 \cdot 000 \pm 0 \cdot 00$} \\
\hline & $18 \cdot 000$ & & $0 \cdot 000$ & & $0 \cdot 000$ & \\
\hline & $7 \cdot 538$ & & $0 \cdot 000$ & & $0 \cdot 000$ & \\
\hline & $17 \cdot 213$ & & $0 \cdot 000$ & & $0 \cdot 000$ & \\
\hline \multirow{6}{*}{ Water (Control) } & $12 \cdot 150$ & \multirow{6}{*}{$12 \cdot 435 \pm 10 \cdot 00$} & $0 \cdot 000$ & \multirow[t]{6}{*}{$0 \cdot 000 \pm 0 \cdot 00$} & $0 \cdot 000$ & \multirow[t]{6}{*}{$0 \cdot 000 \pm 0 \cdot 00$} \\
\hline & $3 \cdot 375$ & & $0 \cdot 000$ & & $0 \cdot 000$ & \\
\hline & $3 \cdot 300$ & & $0 \cdot 000$ & & $0 \cdot 000$ & \\
\hline & $27 \cdot 300$ & & $0 \cdot 000$ & & $0 \cdot 000$ & \\
\hline & $16 \cdot 050$ & & $0 \cdot 000$ & & $0 \cdot 000$ & \\
\hline & & & & & $0 \cdot 000$ & \\
\hline
\end{tabular}

* Significant difference $(P<0 \cdot 001)$ with other RCI values in the same column.

5 weeks p.i. and the reproductive capacity index (RCI: larvae recovered/larvae inoculated) was calculated for each rat.

In vitro study

Larvae of each Trichinella species were cultured in vitro by using the method described by Kapel \& Gamble (2000). The culture medium was Dulbecco's modified Eagle's medium (DMEM) supplemented with $2 \mathrm{~mm}$ L-glutamine, $4500 \mathrm{mg}$ glucose $/ 1,25 \mathrm{~mm}$ HEPES and antibiotics $(50 \mathrm{U}$ penicillin $/ \mathrm{ml}+50 \mu \mathrm{g}$ streptomycin). For each species of Trichinella six $30 \mathrm{ml}$ culture flasks were used. Each flask contained 500 larvae in $5 \mathrm{ml}$ of medium (concentration: 100 larvae $/ \mathrm{ml}$ ). Bile from each of the study animals was added at an amount of $0.5 \mathrm{ml}$ in each of the 3 flasks at a final concentration of $1: 10$ while the remaining 3 flasks served as controls. The flasks were kept at $37{ }^{\circ} \mathrm{C}$. The number of motile (live) and non-motile (dead) larvae in sample optical areas was counted daily under a dissecting microscope at 30 magnifications, and the percentage of motile (live) larvae for each flask was calculated. Counts were done until all larvae were immotile (dead).

\section{Statistical analysis}

Proportions of motile (live) larvae of each Trichinella species cultured in vitro in the presence of each bile or not (control) were analysed using ANOVA. The method is appropriate since the binominal distribution can be approximated by the normal for large samples as in this case $(n=100)$. Since interaction terms were found significant the effect of each combination was tested separately. Multiple comparisons were used to identify significant differences and tests were performed using Tukey's honest significant difference (HSD) test (Miller, 1981). The infectivity (RCI) of each Trichinella species to rats administered with bile or water (control) was analysed using ANOVA as well. The Analysis was performed using SPSS v. 11.

\section{RESULTS}

\section{In vivo study}

The infectivity (RCI) of the 3 Trichinella species to rats administered with bile or water is presented in Table 1. Infection was established in all groups of rats inoculated with $T$. spiralis, but no significant differences in RCI were observed between the various groups of rats administered with bile or water. Infection with $T$. nativa was established only in the group of rats administered with fox bile. Infection with T. nelsoni was established in the groups of rats administered with fox, pig, and sheep bile whereas RCI was significantly higher $(P<0 \cdot 001)$ only in the group of rats administered with fox bile. 

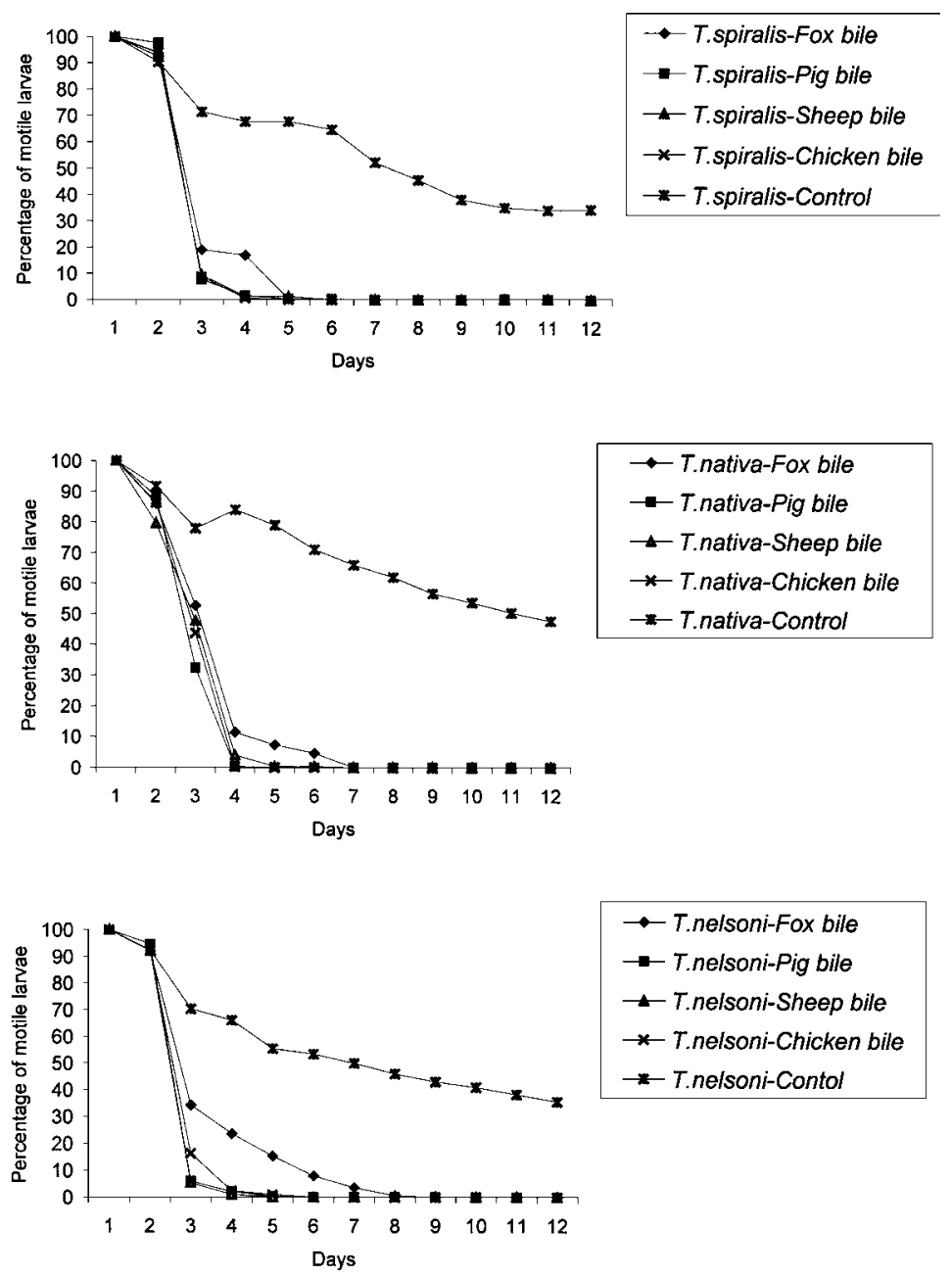

Fig. 1. Percentages of motile (live) Trichinella spiralis, Trichinella nativa and Trichinella nelsoni larvae cultured in the presence of bile from study animals.

\section{In vitro study}

The percentages of motile (live) larvae of the 3 Trichinella species cultured in the presence of bile from any animal were significantly lower $(P<0 \cdot 001)$ compared to their respective control cultures (Fig. 1). On the other hand, the percentage of motile (live) T. nelsoni larvae cultured in the presence of fox bile was significantly higher $(P<0 \cdot 01)$ than in the presence of pig bile $(P<0 \cdot 01)$ or sheep bile.

\section{DISCUSSION}

The mechanisms that are responsible for differences in host susceptibility to various Trichinella species are only poorly understood, but the enteric phase of the life-cycle is a potential point at which the interaction between host and parasite can be stopped (Kapel, 2000). During the intestinal phase of infection both larvae and adults come in contact with bile, and the present study suggests that the composition of the bile influences the infectivity as well as the in vitro survival of larvae.

Several authors have demonstrated that T. nelsoni and $T$. nativa have indeed very low infectivity in rats and that T. spiralis is highly infective (Pozio et al. 1992; Kapel, 2000; Malakauskas, Kapel \& Webster, 2001). Whereas the present study did not demonstrate a further increase in the infectivity of $T$. spiralis with addition of bile, the reproduction of $T$. nativa and T. nelsoni was obviously improved by addition of the fox bile. Although preliminary, this observation may reflect that most sylvatic species of Trichinella initially have been adapted to the carnivore gut environment, and that the domestic $T$. spiralis has developed an ability to reproduce without specific carnivore stimulation.

The results of the in vitro study show that bile, regardless of its origin, had a deleterious effect on the motility of the 3 Trichinella species. Although several factors could be responsible for the increased mortality, the bile may stimulate the initial moulting processes leading to incomplete cuticle transformations that increase mortality.

The mechanism explaining the action of bile on the infectivity of Trichinella sp. is not known. Possible actions of bile on Trichinella larvae are, the digestion of larvae as it has been shown in the case of chicken bile (Barriga, 1981), the inhibition of larvae by 
immune secretory IgA from bile (Jacqueline et al. 1981), the alteration of the parasite's behavioural and nutritional status by exposure to bile (Stewart et al. 1987), the structural reorganization of the surface coat of larvae by exposure to bile (Smith, Selkirk \& Gounaris, 2000), and the modification of tyrosine phosphorylated proteins on the larval cuticle by incubation of the larvae with bile (Allegretti et al. 2001). Nevertheless, all the above mechanism explain the detrimental effect of bile on Trichinella larvae. The exact mechanism explaining the favorable effect of the feeding of carnivore bile on the reproductive capacity of sylvatic Trichinella adult worms in situ in the small intestine of the rats is not known. Apparently, the carnivore bile could survive the digestion by stomach enzymes and the absorption in the small intestine in order to impose its favorable effect on the parasite as observed in the present study.

In conclusion, carnivore bile appears to favour the establishment of sylvatic Trichinella spp.

\section{REFERENCES}

ALLEGRETTI, S., BEAUMONT, V., ROBERT-GANGNEUX, F., CREUZET, C., ROISIN, M. P. \& DUPOUY-CAMET, J. (2001). Detection of tyrosine phosphorylated proteins in Trichinella spiralis $\mathrm{L}_{1}$ larvae. Parasite-Fournal de la Société Française de Parasitologie 8, S59-S61.

BARRIGA, O. O. (1981). Evidence, nature, and implications of the constitutive resistance to Trichinella spiralis in gallinaceous birds. American Fournal of Veterinary Research 42, 1963-1965.

JACQUELINE, E., CRINQUETTE, J., BOUT, D., BARROIS, J. \& VERMEs, A. (1981). Trichinella spiralis in rats: in vivo effects of the bile and in vitro action of secretory $\operatorname{IgA}$ from bile. Annales de Parasitologie Humaine et Comparée (Paris) 56, 395-400.

KAPEL, C. M. O. (2000). Host diversity and biological characteristics of the Trichinella genotypes and their effect on transmission. Veterinary Parasitology 93, 263-278.

KAPEL, C. M. O. \& GAMBLE, H. R. (2000). Infectivity, persistence, and antibody response to domestic and sylvatic Trichinella spp. in experimentally infected pigs. International Fournal for Parasitology 30, 215-221.

MILLER, R. G. JR. (1981). Simultaneous Statistical Inference, 2nd Edn. Springer-Verlag, NY.

MALAKAUSKas, A., KAPEL, C. M. O. \& Webster, P. (2001). Infectivity, persistence and serological response of nine Trichinella genotypes in rats. Parasite-Fournal de la Société Française de Parasitologie 8, 216-222. POZIo, E. (1998). Trichinellosis in the European Union: epidemiology, ecology and economic impact. Parasitology Today 14, 35-38.

POZIO, E., LA ROSA, G., ROSSI, P. \& MURRELl, K. D. (1992). Biological characterisation of Trichinella isolates from various host species and geographical regions. Fournal of Parasitology 78, 647-653.

SMITH, V. P., SELKIRK, M. E. \& GOUNARIS, K. (2000). A reversible protein phosphorylation system is present at the surface of infective larvae of the parasitic nematode Trichinella spiralis. FEBS Letters 483, 104-108.

SMYTH, J. D., GEMMELl, M. \& SMYTH, M. M. (1969). Establishment of Echinococcus granulosus in the intestine of normal and vaccinated dogs. Indian Fournal of Helminthology Srivastava Commemorative volume: 167-178.

STEWART, G. I., DESPOMMIER, D. D., BURNHAM, J. \& RAINES, K. M. (1987). Trichinella spiralis: behavior, structure, and biochemistry of larvae following exposure to components of the host enteric environment. Experimental Parasitology 63, 195-204. 